\title{
IMPLEMENTASI FUZZY SIMPLE ADDITIVE WEGHTING (SAW) SEBAGAI PENDUKUNG KEPUTUSAN PADA BEASISWA PENELITIAN
}

\author{
Rahman Abdillah \\ Program Studi Informatika, Universitas Indraprasta PGRI \\ E-Mail:rabdil.bu@gmail.com
}

\begin{abstract}
Abstrak
Penelitian ini bertujuan untuk mendesain sistem pendukung keputusan (DSS) dalam penentuan peserta yang mendaftar beasiswa penelitian pada program beasiswa penelitian Riset Inovatif Produktif (RISPRO) dari Lembaga Pengelola Dana Pendidikan (LPDP), Kementerian Keuangan RI. Metode penelitian yang digunakan adalah menggunakan metode Fuzzy Simple Additive Weighted (FSAW) yakni dengan cara mengelompokkan dan mengklasifikasikan atribut-atribut dalam kriteria penilaian, kemudian menghitung sesuai dengan bobot kriteria masing-masing, serta meranking hasil akhir penghitungan tersebut. Pengambil keputusan akan dengan cepat mendapatkan rekomendasi nama peserta sesuai dengan ranking dan penilaian nilai akhir. Dengan adanya sistem pendukung keputusan yang telah dirancang ini diharapkan dapat membantu pengambil keputusan dalam menentukan kandidat yang layak mendapatkan beasiswa penelitian RISPRO dengan lebih cepat dan akurat.
\end{abstract}

Kata Kunci : DSS, FSAW, RISPRO, ranking

\begin{abstract}
The aim of this research is designing decision support systems (DSS) which helps the decision maker to acquire the decision applied to the candidates which register to the research scholarship program (Riset Inovatif Produktif/RISPRO) from Lembaga Pengelola Dana Pendidikan (LPDP), held by the Ministry of Finance RI. This research use Fuzzy Simple Additive Weighted (FSAW) as a methodology by classified attributes from each criteria rate, then calculate weights of each criteria and rank them as a final result. Decision maker will get recommendation of potential awardees base on rank and score from each candidates. The presented of decision support systems that has been designed hope can help the decision maker to do the process of determining scholarships recipient faster and accurately.
\end{abstract}

Keywords : DSS, FSAW, RISPRO, rank

\section{Pendahuluan}

Lembaga Pengelola Dana Pendidikan (LPDP) merupakan sebuah lembaga dibawah naungan Kementerian Keuangan yang bertugas untuk mengelola dana pendidikan. Dana pendidikan ini dialokasikan untuk pengembangan pendidikan melalui berbagai program beasiswa dan bantuan dana penelitian. LPDP salah satu misinya adalah mendorong riset strategis dan/inovatif yang implementatif serta menciptakan nilai tambah melalui pendanaan riset, bertanggung jawab untuk berpartisipasi pada pengembangan dan penerapan riset di Indonesia (RISPRO, 2017). Salah satu program beasiswa yang bersifat bantuan penelitian dan non-jenjang pendidikan adalah Program Riset Inovatif Produktif (RISPRO).

Penilaian yang selama ini dilakukan oleh tim reviewer LPDP adalah dengan cara memberikan penilaian melalui form yang dibagikan kepada 3 orang reviewer. Satu orang reviewer akan menilai satu berkas pendaftar. Penilaian dilakukan dalam rapat tersendiri dengan bertatap muka langsung. Dari seluruh berkas yang terkumpul dinilai dengan skala 1 (buruk) sampai dengan 7 (sangat baik), tanpa ada nilai 4. Dengan cara penilaian seperti ini 
terdapat kemungkinan kesalahan penilaian dikarenakan faktor kesalahan pemasukan data dan kesalahan penilaian dari manusia.

Adapun tujuan dari penelitian ini adalah untuk mengimplementasikan Fuzzy Simple Additive Weighted (FSAW) kedalam bagian dari sistem pendukung keputusan (DSS) dalam penentuan beasiswa penelitian RISPRO. Penelitian ini memformulasikan penghitungan aplikasi pendukung keputusan pada beasiswa penelitian RISPRO dengan menggunakan metode Fuzzy Simple Additive Weighted (FSAW). Nilai akhir yang digunakan sebagai bahan acuan pengambilan keputusan akan diurutkan dan kemudian pengambil keputusan dapat mengambil data beberapa peserta dengan nilai yang tertinggi sesuai dengan kebijakan lembaga. Dari hasil pengolahan data dan penghitungan yang didapat, penggunaan metode ini diharapkan dapat membantu pengambil keputusan dalam menentukan calon penerima beasiswa dengan lebih cepat dan akurat.

\section{Tinjauan Pustaka}

\section{Decision Support System (DSS)}

Sistem pendukung keputusan adalah sebuah sistem yang membantu para pengambil keputusan untuk memberikan informasi tambahan dari data yang telah diproses dengan perumusan yang sesuai dengan indikator penilaian sehingga pengambilan keputusan dalam penyelesaian masalah bisa lebih cepat dan akurat.

\section{Logika Fuzzy}

Pada tahun 1962, Prof. Lotfi Astor Zadeh memperkenalkan konsep tentang logika Fuzzy. Logika Fuzzy adalah salah satu metodologi pemecahan masalah yang dapat diimplementasikan pada sistem yang sederhana, embedded system, PC dan jaringan, multichannel, workstation berbasis akuisisi data, dan sistem control (Saleh, 2014). Metodologi ini dapat diterapkan pada perangkat keras dan perangkat lunak. Dalam logika klasik dinyatakan bahwa segala sesuatu bersifat binerm yang berarti hanya memiliki dua kemungkinan, Ya atau Tidak, Benar atau Salah, Baik atau Buruk, dan lain lain. Oleh karena itu, semua dapat mempunyai nilai keanggotaan 0 atau 1 . Dalam logika fuzzy memungkinkan nilai keanggotaan berada diantara nilai 0 dan 1, sehingga hasil dari proses yang menggunakan logika fuzzy akan lebih presisi jika dibandingkan dengan logika biner.

\section{Multiple Atribut Decision Making (MADM)}

Pada dasarnya, proses dari MADM dalam tiga fase, yakni : tahap persiapan komponen yang sesuai dengan situasi, analisis dan men-sintesis informasi (Saleh, 2014). Ada beberapa metodologi yang digunakan dalam penyelesaian masalah FMADM :
a. Simple Additive Weighting Method (SAW)
b. Weighted Product (WP)
c. ELECTRE
d. Technique for Order Preference by Similarity to Ideal Solution (TOPSIS)
e. Analytic Hierarchy Process (AHP)

Sebagai bagian dari pendukung keputusan, model MADM dapat digambarkan kedalam matriks sebagai berikut : 


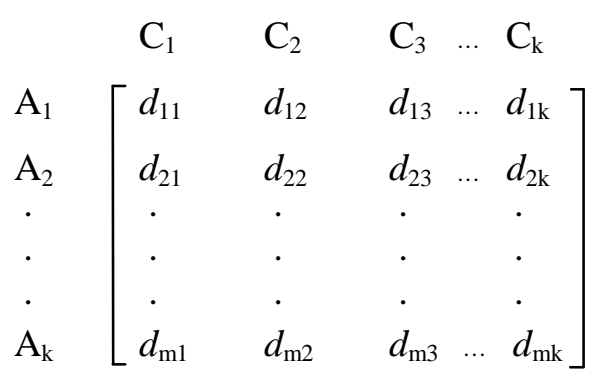

Dalam matriks tersebut $A_{1}, A_{2}, A_{3}, \ldots . A_{m}$ sebagai alternative dan memiliki nilai maksimal $m$, sedangkan $\mathrm{C}_{1}, \mathrm{C}_{2}, \mathrm{C}_{3}, \mathrm{C}_{\mathrm{k}}$ adalah atribut-atribut dalam komponen pendukung keputusan yang digunakan untuk mengukur setiap alternatif.

Hal yang paling penting dalam penggunaan model MADM adalah data yang digunakan tidak stabil dan bisa berubah, sehingga sensitiftas analisis setelah penyelesaian masalah dapat sangat efektif berkontribusi dalam proses pengambilan keputusan (Memariani, 2009). Walaupun hasil penghitungan yang diperoleh cukup sensitive, bisa berubah dan tidak stabil, namun hasil akhir tetap diserahkan kepada seseorang untuk dapat membuat keputusan dalam proses penyelesaian masalah.

\section{Simple Additive Weighted (SAW)}

Metode SAW lebih banyak dikenal dan digunakan dalam menyelesaikan permasalahan pada Multiple Atribut Decision Making (MADM). Metode ini merupakan salah satu metode yang biasanya diterapkan pada sistem pendukung keputusan atau biasa digunakan dalam pemecahan masalah yang melibatkan banyak alternative pilihan sehingga dapat membantu proses pengambilan keputusan dengan lebih cepat dan tepat. Metode SAW adalah salah satu yang paling sering digunakan dikarenakan caranya yang sederhana. Metode SAW sering juga dikenal dengan istilah metode penjumlahan terbobot.

\section{Metodologi Penelitian}

\section{Fuzzy Simple Additive Weighted (FSAW)}

Fuzzy SAW termasuk dalam salah satu metode penyelesaian MADM. Konsep dasar metode Fuzzy SAW adalah mencari penjumlahan terbobot dari rating kinerja pada setiap alternative yang ada pada semua atribut. Metode Fuzzy SAW membutuhkan proses normalisasi matriks keputusan $(\mathrm{X})$ ke suatu skala yang dapat diperbandingkan dengan semua rating alternative yang ada (Saleh, 2014).

$\mathrm{r}_{\mathrm{ij}}=$

$$
\left\{\begin{array}{l}
\frac{x_{i j}}{\operatorname{Max}_{i} x_{i j}} ; j i k a j \text { adalah atribut benefit } \\
\frac{\operatorname{Min}_{i} x_{i j}}{x_{i j}} ; j i k a j \text { adalah atribut cost }
\end{array}\right.
$$

dimana :

$\mathrm{r}_{\mathrm{ij}} \quad=$ nilai rating kinerja ternormalisasi

$\mathrm{X}_{\mathrm{ij}} \quad=$ nilai atribut yang dimiliki dari setiap kriteria

Max $X_{i j}=$ nilai terbesar dari setiap kriteria ij

Min $X_{\mathrm{ij}}=$ nilai terkecil dari setiap kriteria $\mathrm{ij}$

Benefit $=$ jika nilai terbesar adalah terbaik

Cost $=$ jika nilai terkecil adalah terbaik 
Dimana rij adalah rating kinerja ternormalisasi dari alternative $A_{i}$ pada atribut $C_{j} ; i=1,2, \ldots$, $\mathrm{m}$ dan $\mathrm{j}=1,2, \ldots$, .n. Nilai presensi untuk setiap alternative $\left(\mathrm{V}_{\mathrm{i}}\right)$ diberikan sebagai :

$$
V_{i}=\sum_{j=1}^{n} w_{j} r_{i j}
$$

Dimana :

$V_{\mathrm{i}} \quad=$ ranking untuk setiap alternative

$W_{\mathrm{j}} \quad=$ nilai bobot dari setiap kriteria

$\mathrm{r}_{\mathrm{ij}} \quad=$ nilai rating kinerja ternormalisasi

Nilai Vi yang lebih besar mengindikasikan bahwa alternatif $A_{\mathrm{i}}$ lebih terpilih.

\section{Hasil dan Pembahasan}

Sesuai dengan buku Pedoman Riset Inovatif Produktif (RISPRO, 2017) menyebutkan bahwa ada 4 aspek penilaian substansi kelayakan riset, yakni : Kualitas Riset, Luaran Riset, Kemutakhiran Riset dan Rekam Jejak Periset. Dari 4 aspek substansi tersebut akan didapatkan beberapa subaspek penilaian sebagai berikut :

Tabel 1. Skema Penilaian Bantuan Dana RISPRO dalam Rangka Komersialisasi Produk/Teknologi

\begin{tabular}{|c|c|c|}
\hline Aspek & Subaspek & $\begin{array}{c}\text { Bobot } \\
(\%)\end{array}$ \\
\hline \multirow[t]{3}{*}{ Kualitas Riset } & & 40 \\
\hline & a. $\quad$ Roadmap riset terkait implementasi teknologi & 20 \\
\hline & $\begin{array}{l}\text { b. Kelayakan pelaksanaan (kredibilitas mitra, sarana penunjang, serta } \\
\text { uraian tugas, anggaran dan jadwal) }\end{array}$ & 20 \\
\hline \multirow[t]{3}{*}{ Luaran Riset } & & 30 \\
\hline & a. Potensi hak kekayaan intelektual & 15 \\
\hline & b. Nilai strategis dan komersial produk/teknologi & 15 \\
\hline \multirow{4}{*}{ Kemutakhiran Riset } & & 20 \\
\hline & $\begin{array}{l}\text { a. Kepustakaan yang dipakai/digunakan dan publikasi periset (terutama } \\
\text { ketua periset) }\end{array}$ & 5 \\
\hline & b. State of the art & 5 \\
\hline & c. Metode pendekatan & 10 \\
\hline \multirow{3}{*}{ Rekam Jejak Periset } & & 10 \\
\hline & a. Produktivitas riset dan publikasi & 5 \\
\hline & b. Kerja sama riset dengan industri/UKM & 5 \\
\hline
\end{tabular}

Penilaian terhadap setiap aspek dan subaspek dengan cara memberikan skor 1 (satu) sampai dengan 7 (tujuh), tanpa ada nilai 4 (empat). Adapun tata cara penilaian oleh reviewer dilakukan dengan mempertimbangkan hal-hal sebagai berikut :

a. Penilaian proposal RISPRO dilakukan sekurang-kurangnya oleh 3 (tiga) orang reviewer independen yang ditetapkan oleh Direktur Utama LPDP

b. Penilaian proposal RISPRO dimaksud merupakan penilaian terhadap setiap komponen dan subkomponen substansi proposal riset dengan cara mengalikan skor setiap subkomponen dan bobot

c. Nilai akhir hasil penilaian adalah rata-rata dari penjumlahan nilai dari setiap reviewer dengan mempertimbangkan nilai minimum kelulusan (passing grade) dari hasil penilaian setiap reviewer.

Dalam menetapkan penerima Bantuan Dana RISPRO, Direksi LPDP mempertimbangkan rekomendasi reviewer LPDP. 


\section{Determinasi dari Kriteria}

Beberapa aspek kriteria sistem penilaian Program Bantuan Dana RISPRO dalam rangka komersialisasi produk/teknologi adalah sebagai berikut :

$$
\begin{aligned}
& C_{1}=\text { Kualitas Riset-Roadmap } \\
& C_{2}=\text { Kualitas Riset-Kelayakan pelaksanaan } \\
& C_{3}=\text { Luaran Riset-Potensi HKI } \\
& C_{4}=\text { Luaran Riset-Nilai Strategis dan Komersial } \\
& C_{5}=\text { Kemutakhiran Riset-Kepustakaan yang dipakai } \\
& C_{6}=\text { Kemutakhiran Riset-State of The Art } \\
& C_{7}=\text { Kemutakhiran Riset-Metode Pendekatan } \\
& C_{8}=\text { Rekam Jejak-Produktivitas riset dan publikasi } \\
& C_{9}=\text { Rekam Jejak-Kerjasama riset }
\end{aligned}
$$

Penilaian terhadap setiap aspek dan subaspek tersebut dengan cara memberikan skor 1 (satu) sampai dengan 7 (tujuh), dan nilai yang diberikan tanpa ada nilai 4 (empat) untuk menghilangkan nilai tengah dari sistem penilaian. Adapun interpretasi dari setiap nilai adalah sebagai berikut :

- Nilai 1 (satu) berarti "Buruk"

- Nilai 2 (dua) berarti "Sangat Kurang"

- Nilai 3 (tiga) berarti "Kurang"

- Nilai 5 (lima) berarti "Cukup"

- Nilai 6 (enam) berarti "Baik"

- Nilai 7 (tujuh) berarti "Sangat Baik"

Masing-masing jenis bantuan dana dapat dihitung dengan determinasi bobot 1 (satu) sampai dengan 7 (tujuh) dari masing-masing kriteria berdasarkan jenis dan program bantuan dana yang diinginkan oleh pendaftar/periset. Sebagai contoh: beberapa periset memiliki publikasi yang lebih banyak daripada yang lain, namun periset tersebut memiliki rekam produktivitas riset dan publikasi yang lebih rendah daripada yang lain. Beberapa parameter sistem perhitungan nilai tersebut dipersiapkan dengan pemikiran bahwa kualitas SDM periset didasarkan tidak hanya dari faktor kualitas intelektual, namun juga aspek kompetensi yang lain, termasuk, kompetensi sosial, kemampuan komunikasi, kebermanfaatan hasil/produk serta dampak sosial dan ekonomi yang mungkin bisa dihasilkan dari penelitian yang dilakukan periset.

\section{Tabel 2. Kategori Bobot Penilaian}

\begin{tabular}{cc}
\hline $\begin{array}{c}\text { Bobot } \\
\text { Penilaian }\end{array}$ & Kategori \\
\hline 1 & Buruk \\
2 & Sangat Kurang \\
3 & Kurang \\
5 & Cukup \\
6 & Baik \\
7 & Sangat Baik \\
\hline
\end{tabular}

\section{Analisis Data Input}

Studi kasus :

Pada sebuah proses seleksi beasiswa penelitian, 3 orang reviewer memberikan penilaian kepada 5 kandidat penerima beasiswa penelitian. Kuota yang tersedia untuk penerimaan beasiswa penelitian berjumlah 2 orang. Lembaga pemberi beasiswa mencari kandidat yang sesuai dengan kriteria, dan melakukan penghitungan kepada pelamar dengan mengurutkan nilai yang tertinggi (ranking), kemudian menetapkan 2 orang dengan nilai tertinggi sebagai 
penerima beasiswa penelitian. Data yang berhasil terkumpul dari 3 orang reviewer pada saat proses seleksi dapat dilihat pada tabel 3 .

\section{Tabel 3. Data Penilaian Reviewer}

\begin{tabular}{l|c|c|c|c|c|c|c|c|c}
\hline \multirow{2}{*}{$\begin{array}{c}\text { Nama } \\
\text { Pendaftar }\end{array}$} & \multicolumn{10}{c}{ Bobot Penilaian } \\
\cline { 2 - 10 } & $C_{1}$ & $C_{2}$ & $C_{3}$ & $C_{4}$ & $C_{5}$ & $C_{6}$ & $C_{7}$ & $C_{8}$ & $C_{9}$ \\
\hline Drajat & $6,7,6$ & $6,6,5$ & $5,6,6$ & $7,6,6$ & $3,5,5$ & $6,6,7$ & $7,7,6$ & $3,5,6$ & $7,6,7$ \\
\hline Priambodo & $5,7,6$ & $6,5,3$ & $7,5,6$ & $6,6,5$ & $6,5,7$ & $6,3,5$ & $3,5,5$ & $7,7,5$ & $6,5,6$ \\
\hline Reyhan & $7,7,5$ & $5,6,6$ & $3,5,5$ & $7,6,7$ & $7,5,5$ & $7,5,6$ & $6,5,6$ & $5,5,7$ & $7,7,6$ \\
\hline Sukma & $7,7,6$ & $7,3,5$ & $6,5,5$ & $5,6,6$ & $3,2,6$ & $6,7,7$ & $7,7,5$ & $7,6,7$ & $6,6,5$ \\
\hline Yohan & $5,7,7$ & $6,6,7$ & $3,5,6$ & $7,7,6$ & $6,5,7$ & $5,6,5$ & $7,7,6$ & $7,7,5$ & $3,5,5$ \\
\hline
\end{tabular}

Dalam melakukan penghitungan menggunakan metode Simple Additive Weighting (SAW), langkah pertama adalah mendeterminasikan nama-nama pendaftar menjadi alternative (Tabel 4).

Tabel 4. Alternatif

\begin{tabular}{lc}
\hline \multicolumn{1}{c}{ Nama } & Alternatif \\
\hline Drajat & $A_{1}$ \\
\hline Priambodo & $A_{2}$ \\
\hline Reyhan & $A_{3}$ \\
\hline Sukma & $A_{4}$ \\
\hline Yohan & $A_{5}$ \\
\hline
\end{tabular}

Setelah tahap determinasi alternative, selanjutnya memberikan penilaian setiap alternative pada setiap kriteria dengan cara mengambil nilai rata-rata dari setiap komponen. Fuzzy SAW memungkinkan nilai antara 0 dan 1 , sehingga didapat nilai pada tabel 5 .

Tabel 5. Kriteria Rata-rata

\begin{tabular}{c|c|c|c|c|c|c|c|c|c|}
\hline \multirow{2}{*}{ Alternatif } & \multicolumn{10}{|c}{ Kriteria } \\
\cline { 2 - 10 } & $C_{1}$ & $C_{2}$ & $C_{3}$ & $C_{4}$ & $C_{5}$ & $C_{6}$ & $C_{7}$ & $C_{8}$ & $C_{9}$ \\
\hline$A_{1}$ & 6.33 & 5.67 & 5.67 & 6.33 & 4.33 & 6.33 & 6.67 & 6.67 & 6.67 \\
\hline$A_{2}$ & 6.00 & 4.67 & 6.00 & 5.67 & 6.00 & 4.67 & 4.33 & 6.33 & 5.67 \\
\hline$A_{3}$ & 6.33 & 5.67 & 4.33 & 6.67 & 5.67 & 6.00 & 5.67 & 5.67 & 6.67 \\
\hline$A_{4}$ & 6.67 & 5.00 & 5.33 & 5.67 & 3.67 & 6.67 & 6.33 & 6.67 & 5.67 \\
\hline$A_{5}$ & 6.33 & 6.33 & 4.67 & 6.67 & 6.00 & 5.33 & 6.67 & 6.33 & 4.33 \\
\hline
\end{tabular}

Determinasi pada masing-masing kriteria mempunyai nilai total $=1$, sedangkan bobot pada masing-masing kriteria dapat dilihat pada tabel 6.

\section{Tabel 6. Bobot Masing-masing Kriteria}

\begin{tabular}{lc}
\hline \multicolumn{1}{c}{ Kriteria } & Bobot \\
\hline$\left(C_{1}\right)$ Road Map & 0.2 \\
$\left(C_{2}\right)$ Kelayakan pelaksanaan & 0.2 \\
$\left(C_{3}\right)$ Potensi Hak Karya Intelektual & 0.15 \\
$\left(C_{4}\right)$ Nilai Strategis dan Komersial & 0.15 \\
$\left(C_{5}\right)$ Kepustakaan yang dipakai & 0.05 \\
$\left(C_{6}\right)$ State of the art & 0.05 \\
$\left(C_{7}\right)$ Metode Pendekatan & 0.1 \\
$\left(C_{8}\right)$ Produktivitas Riset dan Publikasi & 0.05 \\
$\left(C_{9}\right)$ Kerjasama Riset & 0.05 \\
\hline
\end{tabular}

Dari tabel 6 kita dapat merubah bobot kriteria kedalam matriks dengan data :

$$
W=\left[\begin{array}{lllllllll}
0.2 & 0.2 & 0.15 & 0.15 & 0.05 & 0.05 & 0.1 & 0.05 & 0.05
\end{array}\right]
$$

Dari data tabel 5, jika dirubah kedalam matriks adalah sebagai berikut : 


$X=\left[\begin{array}{lllllllll}6.33 & 5.67 & 5.67 & 6.33 & 4.33 & 6.33 & 6.67 & 6.67 & 6.67 \\ 6.00 & 4.67 & 6.00 & 5.67 & 6.00 & 4.67 & 4.33 & 6.33 & 5.67 \\ 6.33 & 5.67 & 4.33 & 6.67 & 5.67 & 6.00 & 5.67 & 5.67 & 6.67 \\ 6.67 & 5.00 & 5.33 & 5.67 & 3.67 & 6.67 & 6.33 & 6.67 & 5.67 \\ 6.33 & 6.33 & 4.67 & 6.67 & 6.00 & 5.33 & 6.67 & 6.33 & 4.33\end{array}\right]$

Untuk normalisasi matriks X kedalam matriks R diperlukan konstanta matriks $\mathrm{W}$ dan dikalikan dengan matriks X. Untuk kalkulasi dari matriks R diperlukan klasifikasi penilaian kriteria kedalam cost atau benefit.

Tabel 7. Klasifikasi Kriteria

\begin{tabular}{lcc}
\hline \multicolumn{1}{c}{ Kriteria } & Benefit & Cost \\
\hline$\left(C_{1}\right)$ Road Map & $\sqrt{ }$ & - \\
\hline$\left(C_{2}\right)$ Kelayakan pelaksanaan & $\sqrt{ }$ & - \\
\hline$\left(C_{3}\right)$ Potensi Hak Karya Intelektual & $\sqrt{ }$ & - \\
\hline$\left(C_{4}\right)$ Nilai Strategis dan Komersial & $\sqrt{ }$ & - \\
\hline$\left(C_{5}\right)$ Kepustakaan yang dipakai & $\sqrt{ }$ & - \\
\hline$\left(C_{6}\right)$ State of the art & $\sqrt{ }$ & - \\
\hline$\left(C_{7}\right)$ Metode Pendekatan & $\sqrt{ }$ & - \\
\hline$\left(C_{8}\right)$ Produktivitas Riset dan Publikasi & $\sqrt{ }$ & - \\
\hline$\left(C_{9}\right)$ Kerjasama Riset & $\sqrt{ }$ & - \\
\hline
\end{tabular}

Berdasarkan klasifikasi kriteria pada tabel 7, semua kriteria menggunakan penghitungan formulasi benefit, perhitungan normalisasinya adalah sebagai berikut :

$$
\begin{aligned}
& R_{11}=\frac{6.33}{\max \{633 ; 600,639 ; 6,67,633\}}=\frac{6.33}{6.67}=0.95 \\
& R_{21}=\frac{6.00}{\max \{6.39 ; 6.00 ; 6.33 ; 6.67 ; 6.33\}}=\frac{6.00}{6.67}=0.90 \\
& R_{31}=\frac{633}{\max \{633600 ; 6396.676 .33\}}=\frac{6.33}{6.67}=0.95 \\
& R_{41}=\frac{6.67}{\max \{633 ; 600 ; 633 ; 6,67,633\}}=\frac{667}{667}=1 \\
& R_{51}=\frac{633}{\max [6391600,639 ; 6,67,633\}}=\frac{633}{667}=0.95 \\
& R_{12}=\frac{5.67}{\max \{5.67,4,67,5.67,5.00 ; 6.33\}}=\frac{5.67}{6.33}=0.896 \\
& R_{22}=\frac{4.67}{\max \{5,67,467,5,675,00,633\}}=\frac{4.67}{6.39}=0.74 \\
& R_{32}=\frac{5.67}{\max \{5,67,4,67,5675,00,633\}}=\frac{5.67}{6.33}=0.896 \\
& R_{42}=\frac{5,00}{\max [5,67,4,67,567,6,00,633]}=\frac{5.00}{6.33}=0.79 \\
& R_{52}=\frac{633}{\max [5,67,467,6,675,00 ; 633]}=\frac{633}{6.33}=1 \\
& R_{13}=\frac{5,67}{\max [5,67,6,00 ; 4,39 ; 5,33 ; 4,67]}=\frac{5,67}{600}=0.945
\end{aligned}
$$




$$
\begin{aligned}
& R_{23}=\frac{6,00}{\operatorname{mex}[5.67 ; 6.00 ; 4.33 ; 5.33 ; 467]}=\frac{6.00}{6.00}=1 \\
& R_{33}=\frac{4.33}{\max [5,67,6,00 ; 4,33,5,33 ; 4,67]}=\frac{4.33}{6.00}=0.72 \\
& R_{43}=\frac{5.33}{\max [5,67600: 435: 539: 467]}=\frac{5.33}{6.00}=0.89 \\
& R_{53}=\frac{467}{\max (5,67,600 ; 433 ; 5,33 ; 467)}=\frac{467}{6,00}=0.78 \\
& R_{14}=\frac{633}{\max [633,5,67,67,5,67,667)}=\frac{633}{6.67}=0.95 \\
& R_{24}=\frac{5.67}{\max [6.33,5,67,667,5,67,6,67]}=\frac{5.67}{6.67}=0.85 \\
& R_{34}=\frac{6.67}{\max [6.3915,67,6675,67,667]}=\frac{6.67}{6.67}=1 \\
& R_{44}=\frac{5.67}{\max [6.33,5,67,6.67,5,67,6,67]}=\frac{5.67}{6.67}=0.85 \\
& R_{54}=\frac{6.67}{\max \left\{633_{1} 5,67,6,67,5,67,667\right]}=\frac{6.67}{6.67}=1 \\
& R_{15}=\frac{439}{\max \{433 ; 6,00 ; 5.673 .67,6.00\}}=\frac{433}{6.00}=0.72 \\
& R_{25}=\frac{600}{\max [433 ; 600: 567,6,67,600\}}=\frac{600}{600}=1 \\
& R_{35}=\frac{5.67}{\max [4.33 ; 6.00,5.67,3.67,600]}=\frac{5.67}{6.00}=0.945 \\
& R_{45}=\frac{3.67}{\max \{433 ; 6001567,67,600\}}=\frac{3.67}{600}=0.61 \\
& R_{55}=\frac{6,00}{\max \{4.33,6,00,567,67,67,6.00\}}=\frac{6.00}{6.00}=1 \\
& R_{16}=\frac{633}{\max (6.39 ; 4,67,600 ; 6,67,5.39)}=\frac{633}{6.67}=0.95
\end{aligned}
$$

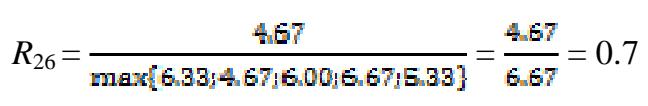

$$
\begin{aligned}
& R_{36}=\frac{600}{\max [6.33 ; 4,67,600,6,67,6.33]}=\frac{6.00}{6.67}=0.9 \\
& R_{46}=\frac{6.67}{\max (6,93 ; 4,67,600 ; 6,67,5.39]}=\frac{6.67}{6.67}=1 \\
& R_{56}=\frac{5.33}{\max \{633 ; 467 ; 600 ; 6,67 ; 5.33\}}=\frac{5.33}{6.67}=0.8 \\
& R_{17}=\frac{667}{\max [667 ; 439 ; 567,693 ; 667]}=\frac{667}{667}=1 \\
& R_{27}=\frac{433}{\max [6.335,676,67,567667)}=\frac{433}{6.67}=0.65
\end{aligned}
$$




$$
\begin{aligned}
& R_{37}=\frac{5.67}{\max \{6.39 ; 5,67,6,675,67,667\}}=\frac{5.67}{6.67}=0.85 \\
& R_{47}=\frac{6.33}{\max \left\{6.33_{i} E_{6} 67,67_{1} E_{1} 67,6.67\right\}}=\frac{6.33}{6.67}=0.95 \\
& R_{57}=\frac{6,67}{\max \left\{633_{i} 5,67,6,67,5,67,667\right]}=\frac{667}{667}=1 \\
& R_{18}=\frac{6.67}{\max \{6.67 ; 6.33 ; 5.67 ; 6,67 ; 6.33\}}=\frac{6.67}{6.67}=1 \\
& R_{28}=\frac{633}{\max \{667,639567,67,633\}}=\frac{6.33}{6.67}=0.95 \\
& R_{38}=\frac{5.67}{\max \{6.67,6.33,5,67,667,633\}}=\frac{5.67}{6.67}=0.85 \\
& R_{48}=\frac{6.67}{\max [6.67,6,33,6,67,6,67,6.33]}=\frac{6.67}{6.67}=1 \\
& R_{58}=\frac{6.33}{\max \left\{6.67,6.33_{1} 5,67,6,67,6.33\right\}}=\frac{6.33}{6.67}=0.95 \\
& R_{19}=\frac{6,67}{\max \{6,67,5,67,6675,67,4,33\}}=\frac{6,67}{6,67}=1 \\
& R_{29}=\frac{5.67}{\max [6.67 ; 5.67 ; 6.67 ; 5.67 ; 433\}}=\frac{5.67}{6.67}=0.85 \\
& R_{39}=\frac{6,67}{\max \{6,67,5,67,667,5,67,433\}}=\frac{667}{6,67}=1 \\
& R_{49}=\frac{5.67}{\max \{6,67,5,67,6,67,6,67,433\}}=\frac{5.67}{6.67}=0.85 \\
& R_{59}=\frac{433}{\max \{6,67,5,67,67,5,67,433\}}=\frac{433}{667}=0.65
\end{aligned}
$$

Dari perhitungan tersebut didapat matriks sebagai berikut :

$$
R=\left[\begin{array}{ccccccccc}
0.95 & 0.896 & 0.945 & 0.95 & 0.72 & 0.95 & 1 & 1 & 1 \\
0.90 & 0.74 & 1 & 0.85 & 1 & 0.7 & 0.65 & 0.95 & 0.85 \\
0.95 & 0.896 & 0.72 & 1 & 0.945 & 0.9 & 0.85 & 0.85 & 1 \\
1 & 0.79 & 0.89 & 0.85 & 0.61 & 1 & 0.95 & 1 & 0.85 \\
0.95 & 1 & 0.78 & 1 & 1 & 0.8 & 1 & 0.95 & 0.65
\end{array}\right]
$$

Untuk selanjutnya, proses perankingan diakhiri dengan normalisasi matriks $\mathrm{R}$ perkalian dengan matriks $W$ (bobot kriteria), perhitungan Vector $(V)$ adalah sebagai berikut :

$V_{1}=(0.2 \times 0.95)+(0.2 \times 0.896)+(0.15 \times 0.945)+(0.15 \times 0.95)+(0.05 \times 0.72)+(0.05 \times$ $0.95)+(0.1 \times 1)+(0.05 \times 1)+(0.05 \times 1)=0.937$

$V_{2}=(0.2 \times 0.90)+(0.2 \times 0.74)+(0.15 \times 1)+(0.15 \times 0.85)+(0.05 \times 1)+(0.05 \times 0.7)+(0.1 \times$ $0.65)+(0.05 \times 0.95)+(0.05 \times 0.85)=0.846$

$V_{3}=(0.2 \times 0.95)+(0.2 \times 0.896)+(0.15 \times 0.72)+(0.15 \times 1)+(0.05 \times 0.945)+(0.05 \times 0.9)+(0.1 \times$ $0.85)+(0.05 \times 0.85)+(0.05 \times 1)=0.897$ 
$V_{4}=(0.2 \times 1)+(0.2 \times 0.79)+(0.15 \times 0.89)+(0.15 \times 0.85)+(0.05 \times 0.61)+(0.05 \times 1)+(0.1 \times$ $0.95)+(0.05 \times 1)+(0.05 \times 0.85)=0.887$

$V_{5}=(0.2 \times 0.95)+(0.2 \times 1)+(0.15 \times 0.78)+(0.15 \times 1)+(0.05 \times 1)+(0.05 \times 0.8)+(0.1 \times 1)+(0.05$ $\mathrm{x} 0.95)+(0.05 \times 0.65)=0.927$

Tabel 8. Hasil perankingan

\begin{tabular}{ccc}
\hline Alternatif & Nilai & Ranking \\
\hline$A_{1}$ & 0.937 & $\mathbf{1}$ \\
$A_{2}$ & 0.846 & 5 \\
$A_{3}$ & 0.897 & 3 \\
$A_{4}$ & 0.887 & 4 \\
$A_{5}$ & 0.927 & $\mathbf{2}$ \\
\hline
\end{tabular}

Dari hasil perhitungan didapat nilai tertinggi yaitu $V_{l}$ dan $V_{5}$, jadi dua kandidat yang layak mendapatkan beasiswa penelitian adalah Drajat $\left(A_{l}\right)$ dan Yohan $\left(A_{5}\right)$

\section{Simpulan dan Saran}

Penelitian ini memformulasikan penghitungan aplikasi pendukung keputusan pada beasiswa penelitian RISPRO dengan menggunakan metode Fuzzy Simple Additive Weighted (FSAW). Nilai akhir yang digunakan sebagai bahan acuan pengambilan keputusan, memiliki selisih yang sedikit untuk kemudian diurutkan, untuk kemudian pengambil keputusan dapat mengambil data beberapa peserta dengan nilai yang tertinggi. Dari hasil penghitungan yang didapat, penggunaan metode ini memungkinkan pengolahan data dengan lebih tepat, cepat dan akurat serta dapat memberikan rekomendasi calon peserta yang layak menerima beasiswa penelitian.

\section{Daftar Pustaka}

Abdullah, L., Adawiyah, R., (2014). Simple Additive Weighting Methods of Multi criteria Decision Making and Applications: A Decade Review. International Journal of Information Processing and Management (IJIPM), Vol 5, Number 1, February 2014

Endra, R. Y., Sukoco, A. (2014). Decision Support System (DSS) for The Determination of Percentage of Scholarship Quantity based Fuzzy Tahani. $3^{\text {rd }}$ International Conference on Engineering \& Technology Development 2014. ISSN 2301-6590

Memariani, A., Amini, A., Alinezhad,A. (2009). Sensitivity Analysis of Simple Additive Weighting Method (SAW): The Results of Change in the Weight of One Attribute on the Final Ranking of Alternatives. Journal of Industrial Engineering 4 (2009) 13-18

Kaur, P., Kumar, S., (2013). An Intuitionistic Fuzzy Simple Additive Weighting (IFSAW) Method for Selection of Vendor. IOSR Journal of Business and Management (IOSR$J B M$ ) Volume 15, Issue 2 (Nov-Dec 2013), PP 78-81 e-ISSN: 2278-487x, p-ISSN: 2319-7668

Kurniawan, Y. I., (2015). Decision Support System for Acceptance Scholarship with Simple Additive Weighting Method. International Conference on Science, Technology and Humanity. ISSN 2477-3328

Lembaga Pengelola Dana Pendidikan Kementerian Keuangan RI. (2015). Pedoman Riset Inovatif Produktif (RISPRO). http://www.lpdp.kemenkeu.go.id/

Prasetiyo, B. (2016). Fuzzy Simple Additive Weighting Method in the Decision Making of Human Resource Recruitment. Lontar Komputer Vol. 7, No.3, Desember 2016. p-ISSN 2088-1541, e-ISSN 2541-5832 